\title{
OS AVANÇOS DOS DIREITOS SOCIAIS E DA EDUCAÇÃO NA CONSTITUIÇÃO FEDERAL DE 1988 E A JUDICIALIZAÇÃO COMO REMÉDIO PARA A MÁ GERÊNCIA DO ESTADO ${ }^{1}$
}

Zilda Maria de Oliveira Lana *

\begin{abstract}
* Pontificia Universidade Católica de Minas Gerais
\end{abstract} Catolica de Minas Crerais

\section{RESUMO}

O presente artigo tem por objetivo discutir os impactos que a inserção dos direitos sociais no rol de normas que tratam sobre os Direitos e Garantias Fundamentais na Constituição da República Federativa do Brasil de 1988 causaram aos cidadãos brasileiros. Reflete sobre o papel assumido pelo Estado Democrático Social na elaboração e implementação de políticas públicas, que sejam capazes de garantir maior efetividade aos direitos prestacionais positivos; e discute sobre o fenômeno da intensificação da judicialização associando o mesmo às más gerências do Estado relacionadas ao direito social à educação.

Palavras chave: Direitos sociais. Judicialização. Educação.

\begin{abstract}
The paperwork presented aims to discuss the impacts of the insertion of social rights within the norms on Fundamental Rights and Guaranties of the Federal Republic of Brazil since 1988 caused on the Brazilian citizens. It talks about the role taken by the Social Democratic State in elaborating and implementing public policies which are capable of guarantee a greater effectiveness of positive rights; it also discuss about the phenomenon of intensification of judicialization associating it to the bad administration of the State related to the social right to education.
\end{abstract}

Keywords: Social rights. Judicialization. Education.

\footnotetext{
${ }^{1}$ Agradeço à Coordenadoria de Aperfeiçoamento de Pessoal de Nível Superior (Capes), pelo financiamento da pesquisa.
} 


\section{INTRODUÇÃO}

Promulgada em 1988, a atual Constituição Federal (CF) constitui documento minucioso que incorporou, na forma de valores e de prescrições impositivas, preocupação com a garantia dos direitos dos cidadãos, dentre os quais se encontram os direitos sociais. Conhecida como Constituição Cidadã (CARVALHO, 2008), a CF/88 está no ápice do Ordenamento Jurídico brasileiro, condicionando todas as demais normas aos seus preceitos e valores, sejam esses expressos ou tácitos.

Fossem suficientes as letras tecidas no documento, a população brasileira viveria com integridade e em condições minimamente dignas. No entanto, os números de pesquisas ainda mostram que a desigualdade, a opressão, a miséria e o analfabetismo ainda continuam expressivamente presentes na nação. Apesar de serem inegáveis as conquistas alcançadas, conforme se verá mais a frente, no desenvolver do texto, também não se pode negar que as políticas públicas de Estado não têm conseguido tornar fáticas as condições ideais apregoadas na Lei Fundamental.

Em uma nação cujo índice de analfabetismo ainda se aproxima dos $9 \%$ entre as pessoas de 15 ou mais anos de idade; que, entre 2007 e 2013, mesmo tendo previsto o ensino fundamental obrigatório e gratuito, ainda não havia conseguido inserir todas as crianças nas escolas; e que apresenta a expressiva porcentagem de $12 \%$ de pessoas com 25 anos ou mais de idade sem instrução, ou com menos de 1 ano de instrução (INSTITUTO BRASILEIRO DE GEOGRAFIA E ESTATÍSTICA, 2015); sem mencionar os demais problemas como distribuição desigual de renda, e precariedade dos Sistemas de Saúde e Educação, não é possível, ainda, afirmar que o Estado tem cumprido seu papel de garantir aos cidadãos os direitos sociais previstos.

Seu dever de elaborar políticas públicas capazes de contemplar os cidadãos com os direitos sociais assegurados constitucionalmente não tem sido desempenhado com primazia. Nesse contexto, de direitos prometidos, porém não cumpridos com integralidade, os cidadãos têm 
recorrido ao Poder Judiciário na busca da satisfação das prestações que cabem ao Legislativo e ao Executivo oferecer, por meio de políticas públicas. Essa busca tem sido expressiva e caracteriza o fenômeno da judicialização, tema também discutido no presente trabalho.

Posto isso, cabe dizer que o objetivo desse texto é refletir sobre os avanços em matéria de direitos sociais ocorridos com a promulgação da Constituição Federal de 1988, assumindo a posição de que apesar de fáticos, pois estão positivados, a realidade de muitos cidadãos ainda não foi contemplada com esses avanços. O que tem provocado o aumento de ações ajuizadas cuja motivação é exatamente a lesão causada pelo descumprimento, por parte do Estado, de suas obrigações na elaboração e aplicação de políticas públicas.

O trabalho desenvolvido apresenta cunho qualitativo (BODGAN; BIKLEN, 1994), e foi construído através de pesquisa bibliográfica (MARCONI; LAKATOS, 2002), recorrendo-se a fontes primárias e secundárias de informação, como artigos, dissertações, livros e normas jurídicas, com a finalidade de refletir sobre os assuntos apresentados.

\section{OS DIREITOS FUNDAMENTAIS DE NATUREZA SOCIAL NA CONSTITUIÇÃO FEDERAL DE 1988 E A EDUCAÇÃO}

Ao introduzir preceitos que tutelam sobre o direito social no rol de normas que se destinam ao tratamento dos direitos e das garantias fundamentais, a Constituição Federal de 1988 inovou e rompeu com as posturas tradicionais(características das constituições anteriores à contemporânea e a partir daquela de 1934, que atrelavam os direitos sociais aos direitos econômicos), que abriam a possibilidade de diminuição da efetividade e da eficácia desses direitos (COSTA, 2011; SARLET, 2001) por valorizar sobremaneira o indivíduo e a economia em detrimento do social.

Nesse sentido, novas configurações foram estabelecidas para a Constituição Federal de 1988. A título de exemplo, tem-se o fato de o artigo $6^{\circ}$ (que trata sobre os Direitos sociais) estar disposto no Título II 
(Dos Direitos e Garantias Fundamentais) e capítulo II (Dos Direitos Sociais, que elenca aqueles que são considerados direitos sociais, estando entre esses o direito à educação) da Carta Magna. O que lhe conferiu pelo expresso no artigo $5^{\circ}, \S 1^{\circ}$, a condição de aplicabilidade imediata, cabendo ao Estado agir, da melhor forma possível, na regulamentação e eficiência no uso dos recursos públicos e na efetividade em seu papel promotor de políticas públicas capazes de preencher as expectativas geradas por essa previsão constitucional (COSTA, 2011).

Os direitos fundamentais, positivados na Carta Magna,têm como intenção garantir, aos cidadãos da nação que tutela, o mínimo necessário para a existência de uma vida digna, com acesso a bens materiais, à cultura, à saúde, à educação e ao lazer. No entanto, sabe-se que, diante de um país com histórico de desigualdade, discriminação e opressão, apenas ter belas palavras em um texto jurídiconão configura garantia de produção de efeitos concretos nas vidas de seus destinatários.

Desse modo, rompendo com os preceitos de um Estado Liberal, a instituição de um Estado Social Democrático de Direito, conforme constante no preâmbulo da Constituição Federal de 1988, implica no comprometimento do Poder Público para a satisfação de um mínimo existencial a todos os seus cidadãos, através de certa intervenção na economia e asseguração de um mínimo de igualdade, liberdade e condições materiais, além de promoção da justiça social, a fim de garantir uma existência digna aos sujeitos(SARLET, 2001).

\begin{abstract}
A teoria do "mínimo existencial" destina ao indivíduo um direito subjetivo que objetiva garantir uma existência digna mediante a efetivação de serviços básicos como o de saúde (saneamento) e educação básica, além de alimentação, por exemplo. Um "mínimo" sem o qual não é possível a sobrevivência do homem e que, apesar de não apresentar um conteúdo predefinido deve ser respeitado e garantido. Por assim dizer, o "mínimo existencial" também deve ser observado em sede dos direitos sociais [...] Essa garantia impõe não somente o afastamento do indivíduo de situações de míngua, mas também garante o mínimo de inserção no contexto social, onde o ente estatal não pode se afastar, devendo atuar positivamente no sentido da asseguração desse mínimo. (COSTA, 2011, p. 48-49)
\end{abstract}

Essa previsão legal de garantia de uma existência digna rompeu, 
ou ao menos tentou romper, com a política de privilégios que prevaleceu por muito tempo no Estado, substituindo-os por direitos. Nas relações de privilégio, aqueles que hoje se constituem como direitos, inclusive fundamentais, como acesso à educação e à saúde, eram regalias de uns poucos mais abastados.

No entanto, apesar desse rompimento, e da positivação dos direitos sociais, também não se pode negar a precariedade com que os mesmos vêm sendo tratados e efetivados.

Sarlet (2001) diz sobre uma crise dos Direitos Fundamentais, que tem implicado em uma descrença nos mesmos, principalmente, por parte da massa excluída da população, que volta a encará-los como privilégios, já que a eles é restrito o acesso a esses direitos.

Para que os Direitos Fundamentais Sociais, situados no artigo $6^{\circ}$ da Carta Magna, possam ser percebidos e os cidadãos gozem dos mesmos, é necessário que o Estado assuma uma postura ativa, caracterizando os chamados Direitos de Prestação. Esses que marcam a passagem de um Estado Liberal para outro Democrático de Direito e implicam na intervenção do Estado na vida dos cidadãos oferecendo-lhes condições materiais de acesso e disfrute de seus direitos.

Os direitos sociais prestacionais (positivos) constituem
expressão direta do Estado Social e, portanto, produto,
complemento e limite do Estado liberal de Direito e dos
direitos de defesa, especialmente dos clássicos direitos de
liberdade de matriz liberal-burguesa. Os direitos sociais (na
sua dimensão prestacional) encontram-se, neste contexto,
intimamente atrelados às tarefas do Estado como Estado
Social, o qual justamente deve zelar por uma adequada e
justa distribuição e redistribuição dos bens existentes.
(SARLET, 2001, p. 19)

Incluso na lista de Direitos Sociais, o direito à educação é um dos exemplos que demanda uma postura ativa por parte do Estado. Previsto na Constituição de 1988 no art. 6º no capítulo III, seção I (art. 205 a 214) e em outras normas jurídicas, como a Lei de Diretrizes e Bases da Educação Nacional (BRASIL, 1996), bem como em Decretos, Pareceres e Planos, a educação é condição essencial à formação humana ética e integral dos seres humanos, sem a qual se tem comprometido o 
desenvolvimento de uma sociedade e o exercício da cidadania.

[...] vale lembrar que o direito à educação não se reduz ao direito do indivíduo de cursar o ensino fundamental para alcançar melhores oportunidadesde emprego e contribuir para o desenvolvimento econômico da nação. Deve ter como escopo o oferecimento de condições para o desenvolvimento pleno de inúmeras capacidades individuais, jamais se limitando às exigências do mercado de trabalho, pois o ser humano é fonte inesgotável de crescimento e expansão no plano intelectual, físico, espiritual, moral, criativo e social. O sistema educacional deve proporcionar oportunidades de desenvolvimento nestas diferentes dimensões, preocupando-se em fomentar valores como o respeito aos direitos humanos e a tolerância, além da participação social na vida pública, sempre em condições de liberdade e dignidade. (DUARTE, 2004, p. 115).

Ao estabelecer a educação como direito de todos e dever do Estado, a Carta Magna abre espaço para a necessidade de elaborações do modus operandi que permitirá aos cidadãos que estão sob as égides dessa Lei Maior desfrutar de seus direitos. Assim, percebe-se a necessidade do estabelecimento das políticas públicas que farão concretizar as imposições constitucionais. Políticas essas que são prerrogativas dos poderes representativos (Legislativo e Executivo) e se "[...] tornam os grandes eixos orientadores da atividade estatal.” (COMPARATO, 1998 ${ }^{2}$ apudDUARTE, 2004, p. 115).

Ao colocar dessa forma na Constituição, tem-se formada uma relação jurídica, na qual de um lado têm-se sujeitospossuidores do direito, e de outro aquele que tem o dever de garantir aos primeiros o acesso e efetividade desse direito. Nesse caso a relação estabelecida dá-se entre um particular e o ente público, na figura do Estado.

Complementarmente, quando se observa o disposto no art. 208, em seu $\S 1^{\circ}$, que diz que "o acesso ao ensino obrigatório e gratuito é direito público subjetivo" (BRASIL, 1988), tem-se que essa relação, além de ser estabelecida entre sujeito e Estado, também configura a possibilidade de exigir, judicialmente, o cumprimento da obrigação de prestação do Estado que por ventura possa não ter sido efetivada.

${ }^{2}$ COMPARATO, F.K. Ensaio sobre o juízo de constitucionalidade de políticas públicas. Revista de Informação Legislativa, Brasília: Senado Federal, n.138, p.39-48, abr./jun. 1998. 
Em outras palavras, o direito público subjetivo confere ao indivíduo a possibilidade de transformar a norma geral e abstrata contida num determinado ordenamento jurídico em algo que possua como próprio. A maneira de fazê-lo é acionando as normas jurídicas (direito objetivo) e transformando-as em seu direito (direito subjetivo). O interessante é notar que o direito público subjetivo se configura como um instrumento jurídico de controle da atuação do poder estatal, pois permite ao seu titular constranger judicialmente o Estado a executar o que deve. (DUARTE, 2004, p. 113)

Apesar de todas as mudanças ocorridas, com a consolidação do Estado Social Democrático de Direito, a promulgação da CF de 1988, que forneceu regime jurídico diferenciado aos direitos sociais, dentre os quais se situa a educação, e, ainda, conferiu a conquista da prescrição constitucional prevendo direitos sociais como direito público subjetivo, ainda não foi possível assegurar o cumprimento efetivo e abrangente desses direitos a todos os cidadãos brasileiros.

Dessa forma, fatores como a precarização de estrutura e recursos, bem como a má governabilidade e a corrupção, atuam como verdadeiras barreiras à efetivação e asseguração de que todos os cidadãos gozem, com plenitude, de seus direitos sociais.

E diante dessa situação, de direitos garantidos, porém não efetivados, muitos cidadãos, grupos de pessoas e entidades específicas têm recorrido ao Poder Judiciário, na expectativa de que, através de intervenção dos tribunais, seus direitos possam ser usufruídos.

Nas palavras de Sousa $\operatorname{Santos}^{3}$ (2007, p. 17) citado por Silveira (2011, p.32)

[...] a precarização dosdireitos econômicos e sociais passa a ser um motivo deprocura do judiciário. Muita da litigação que hoje chega aos tribunais deve-se ao desmantelamento do Estadosocial (direito laboral, previdência social, educação, saúde, etc.).

Essa recorrência ao judiciário para tentar solucionar as más gerências do Estado na deficitária prestação de suas obrigações positivas, tem configurado o fenômeno da expansão da judicialização.

\footnotetext{
${ }^{3}$ SANTOS, B. S.Para uma revolução democrática da justiça. São Paulo: Cortez,
} 2007. 
Nas palavras de Sierra,

[...] a judicialização da política pública, no Brasil, ocorre em função da escassez de políticas que assegurem a efetivação dos direitos de cidadania. De certo modo, não é sobre o reconhecimento da autonomia do sujeito ou da exigência por participação no controle social que aumentam os processos judiciais, mas é da cobrança pelo acesso aos serviços públicos, principalmente, de saúde, educação e assistência. Muitos desses processos são ajuizados na expectativa de que os juízes forcem o governo a cumprir o direito. (SIERRA, 2011, p. 260)

Será sobre esse fenômeno que o tópico seguinte discutirá, abordando o tema da judicialização relacionado à educação.

\section{A JUSTIÇA COMO REMÉDIO PARA A MÁ GERÊNCIA DO ESTADO NA GARANTIA DO ACESSO AOS DIREITOS SOCIAIS: O FENÔMENO DA JUDICIALIZAÇÃO E EDUCAÇÃ̃o}

Conforme elencado em cláusula pétrea constitucional (art. 60, § $4^{\circ}$, inciso III), o Brasil apresenta a clássica tripartição dos Poderes Públicos, na qual se distinguem os Poderes Legislativo, Executivo e Judiciário, que, conforme exposto no art. $2^{\circ}$ da Constituição Federal, devem ser harmônicos e independentes entre si, apresentando estrutura e funções bem definidas, conforme elencado no título IV, capítulos I, II, III e IV do mesmo documento normativo. (BRASIL, 1988)

Apesar de toda essa especificação quanto às prerrogativas das repartições das funções estatais nessas três formas de Poder, não são raros os casos em que um desses desempenha função atípica de suas originais. A título de exemplo de algumas dessas funções atípicas, podese citar a baixa de Medidas Provisórias pelo chefe do Executivo, no desempenho de função legislativa, e a ação do judiciário na aprovação de Súmulas Vinculantes (BRASIL, 1988) que vinculam,às mesmas elaboradas, ações do judiciário e administração pública executiva.

É importante esclarecer aqui que, embora se esteja chamando de funções atípicas, por apresentarem natureza diversa do Poder do qual se 
fala, não se deve associar tal característica à ilegalidade. Ou seja, mesmo que atípicas muitas funções desempenhadas por determinado Poder, que podem parecer estranhas ao mesmo, não constituem infração e nem ação ilegal. Ao contrário, podem ser funções atípicas previstas em normas constitucionais.

A divisão engessada dos três poderes foi elaborada para um modelo de Estado que se diz "Liberal". Nesse, a primazia é a defesa dos direitos individuais e econômicos, de propriedade privada. E ao judiciário cabe a tutela dos direitos patrimoniais, através do direito civil e penal. (CARVALHO, 2014).

No entanto, em um Estado que se diz Democrático de Direito apoiado em valores sociais, como é o caso do Brasil, essa divisão rígida não pode ser comportada, pois diante da incapacidade dos poderes representativos, Legislativo e Executivo, de atender às demandas sociais, através das políticas públicas, o Judiciário passa a compartilhar tal responsabilidade (CARVALHO, 2014), tentando, ao menos no caso concreto, através dos litígios judiciais, amenizar as más gerências do Estado.

A Constituição Federal de 1988, já em seu Preâmbulo, explicita a todos as pretensões e intenções dos constituintes, representantes do poder do povo, e os valores que devem orientar a sociedade brasileira. Ao instituir um Estado que busca assegurar a seus cidadãos o exercício dos direitos sociais, o mesmo se compromete a garantir a seu povo um mínimo de bem-estar social, e de condições necessárias ao exercício da cidadania.

Conforme apontado, o preâmbulo da Constituição Federal de 1988 institui o país como:

[...] um Estado Democrático, destinado a assegurar o exercício dos direitos sociais e individuais, a liberdade, a segurança, o bem-estar, o desenvolvimento, a igualdade e a justiça como valores supremos de uma sociedade fraterna, pluralista e sem preconceitos, fundada na harmonia social [...] (BRASIL, 1988, grifos nossos).

Assim, para o cumprimento do papel do Estado de proporcionar o 
bem estar social, é necessária a elaboração de políticas públicas, prerrogativa do Legislativo e do Executivo. No entanto, diante de limitações de ordens diversas, esses acabam não desempenhando com maestria o papel que lhes é destinado. E assim, acaba sendo destinado ao judiciário o papel de atuar complementando e tentando tapar essas lacunas.

Nesse cenário, então, se configuram as atuações atípicas dos Poderes, que em consonância com o modelo de Estado não se podem ver engessados em suas funções. Mas sim atuar, claro dentro de suas limitações, em prol da consolidação das orientações constantes no preâmbulo e normas constitucionais.

Decorrente desse contexto surge então uma participação mais ativa do judiciário na busca de aumentar a efetividade das políticas públicas. Participação essa que caracteriza um fenômeno que tem sido bem estudado por pesquisadores, não apenas da área jurídica, mas também de áreas outras, como saúde e educação. Trata da judicialização. "Quando o Estado perde a capacidade de assegurar direitos sociais, o Poder Judiciário passa a cumprir esse papel. Dessa forma, a Justiça ganha novas prerrogativas políticas, até então exclusivas dos poderes representativos." (CARVALHO, 2014, p. 438).

Mesmo ciente da possibilidade de concepções diversas para o termo judicialização, a seguir seguem duas concepções, que se coadunam às demais linhas aqui tecidas, e melhor contribuem para a compreensão desse fenômeno no cenário educacional, o qual se discutirá mais à frente.

Para Tate e Vallinder ${ }^{4}$ (1995) citados por Aragão (2013) quando um terceiro provoca o judiciário, e esse atua na revisão de atos do Executivo e do Legislativo, apoiado nas prescrições e orientações constitucionais, influenciando as decisões das instituições políticosociais, tem se caracterizada a judicialização. "[...] a ideia é que, ao encontrar uma lacuna na atuação do Legislativo [e do Executivo], o Supremo Tribunal Federal [e demais tribunais] analisa, julga e decide

${ }^{4}$ TATE, C. Neal; VALLINDER, Torbjörn. The global expansion of judicial power. New York: New York Univ. Press, 1995. 
ações e atos normativos". (ARAGÃO, 2013, p. 69).

Complementarmente, para Barroso,

[A] Judicialização significa que algumas questões de larga repercussão política ou social estão sendo decididas por órgãos do Poder Judiciário, e não pelas instâncias políticas tradicionais: o Congresso Nacional e o Poder Executivo em cujo âmbito se encontram o Presidente da República, seus ministérios e a administração pública em geral. Como intuitivo, a judicialização envolve uma transferência de poder para juízes e tribunais, com alterações significativas na linguagem, na argumentação e no modo de participação da sociedade.(BARROSO, 2009, p.73)

Esse fenômeno da judicialização está associado à redemocratização do país. Para Aragão (2013, p. 69) “o instituto da judicialização [...] foi adotado [...] confirmando-se como efeito da evolução das sociedades democráticas e da necessidade de se atenderem às demandas dos cidadãos por legalidade e legitimidade dos atos dos poderes constituídos."

Nesse movimento, de redemocratização, toda a estrutura social e as relações nelas mantidas adquirem novas conformações. Um maior número de pessoas se torna consciente de seus direitos e dos deveres do Poder Público; ocorre a consolidação, ao menos no papel, dos direitos fundamentais; e a população começa a ter maior acesso à informação.

Barroso (2009, p. 73) defende que uma outra causa para esse fenômeno da judicialização teria sido a "constitucionalização abrangente", que implicou na inserção, no documento constitucional, de matérias que antes eram tratadas no âmbito das legislações ordinárias e das políticas.

Essa inserção de temas, antes exclusos, como os direitos sociais, nas normas constitucionais, dentro de um capítulo próprio, trouxe grandes impactos e mudanças nas vidas dos cidadãos, pois, a partir daí, toda inobservância e ingerência do Estado quanto ao cumprimento dos direitos constitucionais dos cidadãos abre espaço para a possibilidade de ocorrência de uma demanda judicial por parte daquele que se sente lesionado. Já que "se os direitos são reconhecidos por um ordenamento jurídico [e estão positivados em norma constitucional], torna-se 
imprescindível que haja possibilidade de fazer com que o Poder Público [Judiciário] cumpra com seus deveres em caso de omissão ou ação irregular" (SILVEIRA, 2011, p.31).

A própria Constituição Federal em seu art. $5^{\circ}$, inciso XXXV declara que "A lei não excluirá da apreciação do Poder Judiciário lesão ou ameaça ao direito" (BRASIL, 1988). E ainda, apresenta dispositivos, como mandado de injunção, ação civil pública, e mandado de segurança (ARAGÃO, 2013; SIERRA, 2011), através dos quais será possível atender às demandas sociais por acesso à justiça na busca da efetivação dos direitos dos cidadãos.

Como apontaram Vianna, Burgos e Salles (2007),

\begin{abstract}
A invasão do direito sobre o social avança na regulação dos setores mais vulneráveis, em um claro processo de substituição do Estado e dos recursos institucionais classicamente republicanos pelo judiciário [...]O juiz tornase protagonista direto da questão social. Sem política, sem partidos ou uma vida social organizada, o cidadão volta-se para ele, mobilizando o arsenal de recursos criado pelo legislador a fim de lhe proporcionar vias alternativas para a defesa e eventuais conquistas de direitos.
\end{abstract}

Esse protagonismo do Judiciário apesar de revelar que os sujeitos possam estar mais cientes de seus direitos e ativos na busca dos mesmos, também revela outra face do cenário das políticas públicas brasileiras. Pois se de um lado tem-se o Judiciário como "ferramenta" de acesso aos direitos sociais, de outro tem-se evidenciada a baixa efetividade das políticas públicas sociais, como aquelas que dizem respeito ao direito de acesso e permanência na educação.

A precarização na oferta de instrumentos de efetivação dos direitos sociais se constata no grande número de ações ajuizadas. É o que demonstram alguns estudos realizados por autores que se dedicaram a estudar o ingresso no judiciário por motivos relacionados à educação.

Amaral (2013), por exemplo, apresenta resultados quantitativos a respeito do ingresso no judiciário por questões relacionadas ao Ensino Superior, e revela que, embora tenha sofrido oscilações, entre 1990 e 2008, o aumento de ingressantes no ensino superior foi acompanhado por um aumento no acesso ao judiciário para tratar sobre questões diversas 
relacionadas a esse nível de ensino.

Volpe (2012) analisa, sob a ótica do conceito de mínimo existencial, a atuação do Supremo Tribunal Federal na busca pela efetivação de direitos sociais no Brasil.

Cury e Ferreira (2009) trazem exemplos de ações judiciais que envolvem a educação e o Poder Judiciário, por meio de motivos diversos, dentre os quais, a regularização de fornecimento de merenda escolar; a oferta de transporte escolar gratuito para estudantes; a obrigatoriedade de lotação de cargos para professores que estejam vagos; o fornecimento de educação especializada; e a adequação de unidade escolar para o recebimento de aluno com deficiência física.

Silveira (2012) analisando a atuação do Tribunal de Justiça do Estado de São Paulo, em litígios envolvendo a educação, encontrou decisões dos tribunais a respeito de temas diversos, como acesso e permanência na educação, transporte escolar, fechamento de creche em período de férias, condições de funcionamento das escolas, e outros. Interessante apontar que a autora identificou que "O recurso judicial para requisição de uma vaga na educação básica e para o oferecimento de serviços que impedem a permanência do aluno na escola foram os conflitos mais presentes no conjunto estudado" (SILVEIRA, 2012, p. 359). E ainda que "a procura pelo Judiciário é em sua maioria a busca pela efetivação de um direito" (p.361) evidenciando a violação de direito constitucional social de acesso e permanência na escola e a carência na efetivação das políticas públicas.

Assim, mesmo diante dos avanços decorrentes do estabelecimento de um modelo de Estado Social Democrático de Direito, percebe-se pelo volume de ações judiciais e pela expressividade de trabalhos sobre o tema, que o país ainda não foi capaz de garantir a eficácia das normas e a eficiência dos recursos públicos para a promoção da efetividade dos direitos sociais, dentre os quais a educação.

Desse modo, esses "remédios judicias", que permitem corrigir as más gerências do Estado certamente conferiram, juntamente com a conquista dos direitos sociais, avanços para a sociedade. 
No entanto, deve-se questionar até que ponto esses remédios jurídicos são capazes de corrigir a insuficiência ou irregularidade de atuação do Estado no cumprimento dos deveres e obrigações prestacionais que lhe cabem.

Apesar de o litígio envolver a busca individual, ou de pequenos grupos por seus direitos, a decisão do juiz resolve um caso concreto, mas não garante o atendimento da coletividade detentora dos mesmos direitos sociais. Ademais, os procedimentos, as implicações e os desdobramentos produzidos pelo Judiciário, nas ações litigiosas, são consideravelmente diferentes daqueles produzidos pelo Legislativo e pelo Executivo na elaboração e execução de políticas públicas.

\begin{abstract}
Em primeiro lugar, enquanto as instituições representativas imprimem um caráter coletivo à efetivação de políticas públicas de Educação, o Judiciário o faz no caso concreto e o direito tutelado é exclusivo do indivíduo que ajuizou a ação. Em segundo lugar, ao contrário dos demais poderes, o Judiciário só pode agir quando acionado, de acordo com o princípio da inércia inicial do juiz. Esse princípio implica que o juiz não pode dar início a um processo, é apenas a parte quem tem o direito de fazê-lo. Assim, o controle judicial de políticas públicas ocorre a partir da tomada de decisão do juiz diante de uma ação judicial. Essas características e especificidades do controle judicial de políticas públicas tornaram a judicialização da política objeto de críticas, que dizem respeito à qualidade da democracia que se consolida judicialmente. A democracia, conforme institucionalizada no texto de 1988, depende da universalização dos direitos, algo que o Judiciário não pode fazer. (CARVALHO, 2014, p. 446).
\end{abstract}

Logo, mesmo sendo um remédio, por vezes, eficiente para a garantia de direitos sociais feridos, o ingresso em juízo não garante a todos o gozo dos mesmos. Apenas o faz, a depender do entendimento e da decisão do(s) juiz(es) e desembargador(es), para casos concretos, exibindo a limitada produção de efeito que o judiciário pode conferir.

Isso significa reconhecer que o direito à educação só se efetiva mediante o planejamento e a implementação de políticas públicas. Em outras palavras, a satisfação do direito não se esgota na realização do seu aspecto meramente individual (garantia de uma vaga na escola, por exemplo), mas abrange a realização de prestações positivas [políticas públicas] de natureza diversa por parte de poder público[...] (DUARTE, 2007, p. 710). 
Em analogia à Ciência da Saúde, o Judiciário seria como um soro, capaz de tratar um mal já instalado no corpo de um paciente, eficiente no tratamento de alguém que já se vê infectado por um veneno. Esse soro é usado no tratamento pós-infecção. Por sua vez, o Legislativo e o Executivo seriam como uma vacina, mecanismo capaz de evitar a instalação de uma determinada doença, que deve ser administrada antes da exposição ao agente causador da mesma, sendo eficiente no combate e na prevenção.

Desse modo, o Judiciário pode ser eficiente no combate a um mal já instalado, que compromete a integridade e formação humana de sujeitos específicos que recorrem ao mesmo. No entanto, para que se possa evitar a necessidade de uso desse "remédio" é importante investir na "imunização" dos cidadãos, ou seja, investir em políticas públicas capazes de evitar a "infecção", e garantir o acesso efetivo dos cidadãos aos direitos sociais.

\section{CONSIDERAÇÕES FINAIS}

Por tudo exposto, percebe-se que os cidadãos brasileiros conquistaram grandes avançosem relação às normas positivadas em nosso sistema jurídico. Esses que podem ser evidenciados pela análise da Carta Magna, documento jurídico de maior hierarquia que condiciona todas as demais normas aos valores e preceitos expostos em suas páginas.

Dentre esses avanços, indubitavelmente, os sociais merecem destaque, pois receberam maior relevância e importante vinculação da atividade do Estado na promoção do mínimo existencial. Mesmo não sendo capaz de garantir que esses avanços nos direitos sociais atinjam a todas as populações da nação, ainda assim, conta-se com a possibilidade de exigir, em juízo, aquele direito que tem sido negado à(s) mesma(s).

Embora não seja a melhor forma de fazer cumprir as obrigações do Estado, o judiciário se revelou como importante aliado da população lesionada que não têm garantidos os direitos expostos no art. $6^{\circ}$ da Constituição Federal, como a garantia de acesso e/ou as condições de 
permanência no sistema educacional, por exemplo.

A melhor forma de garantir o acesso integral aos direitos sociais de prestação positiva é por meio do estabelecimento, por parte do Estado, de políticas públicas de amplo alcance e efetividade, fazendo cumprir seu papel estabelecido quando da proposta do regime Democrático apoiado em valores sociais e garantidor de uma existência digna a seus cidadãos, tal como exposto na Constituição.

\section{REFERÊNCIAS}

AMARAL, Claudia Tavares do. Demandas judiciais em questões referentes ao ensino superior. In: SIMPÓSIO BRASILEIRO DE POLÍTICA E ADMINISTRAÇÃO DA EDUCAÇÃO, 26.,2013, Recife/PE.Anais...Recife: ANPAE, 2013. Disponível em $<$

http://www.anpae.org.br/simposio26/1comunicacoes/ClaudiaTavaresdoA maral-ComunicacaoOral-int.pdf>. Acesso em: 26 jun. 2015.

ARAGÃO, José Carlos Medeiros de. Ativismo judicial e judicialização da política (Constituição de 1988) - instrumentos constitucionais de judicialização da política no Brasil. In: ARAGÃO, José Carlos Medeiros de. Judicialização da política no Brasil: influência sobre atos interna corporis do Congresso Nacional. Brasília: Câmara dos Deputados, 2013. $139 \mathrm{p}$.

BARROSO, Luís Roberto. Judicialização, ativismo judicial e legitimidade democrática. Revista Direito do Estado. Salvador, ano 4, n. 13, p. 71-91, jan./mar. 2009.

BODGAN, Robert C; BIKLEN, Sari Knopp. Investigação qualitativa em educação. Portugal: Porto Editora, 1994.

BRASIL. Constituição (1988).Constituição da RepúblicaFederativa doBrasil. Brasília:Senado, 1988.

BRASIL. Lei no 9.394 de 20 de dezembro de 1996. Estabelece as diretrizes e bases da educação nacional.Diário Oficial da União, Brasília, 23 dez. 1996. Disponível em:

<http://www.planalto.gov.br/ccivil_03/Leis/L9394.htm>. Acesso em: 03 jul. 2015.

CARVALHO, Adriana Duarte de Souza. A educação e o Poder Judiciário: a busca por vagas em escolas públicas no Brasil. Revista

Eletrônica Direito e Política. Itajaí, v. 9, n. 1, p. 431-449, $1^{\circ}$ quadrimestre 2014. Disponível em:

<http://www6.univali.br/seer/index.php/rdp/article/viewFile/5762/3139>. 
Acesso em: 26 jun. 2015.

CARVALHO, José Murilo de. Cidadania no Brasil: o longo caminho. 10. ed. Rio de Janeiro: Civilização Brasileira, 2008.

COSTA, Álisson da Silva.A efetivação dos direitos sociais no Estado Democrático de Direito brasileiro: uma abordagem crítico-reflexiva da análise econômica do direito a partir de Richard Posner e a proposta de Ronald Dworkin. 2011. 139f. Dissertação (Mestrado) - Programa de Pós-Graduação em Direito, Pontifícia Universidade Católica de Minas Gerais, 2011.

CURY, Carlos Roberto Jamil; FERREIRA, Luiz Antônio Miguel. A judicialização da educação. Revista CEJ, Brasília, v. 1, p.32-45, 2009.

DUARTE, Clarice Seixas. A educação como um direito fundamental de natureza social. Educação \& Sociedade. Campinas, v. 28, n.100, p. 691 713, out. 2007. Disponível em:

$<$ http://www.scielo.br/scielo.php?pid=S010173302007000300004\&script =sci_abstract\&tlng=pt $>$. Acesso em: 06 jul. 2015.

DUARTE. Clarice Seixas. Direito Público subjetivo e políticas educacionais. São Paulo em perspectiva, v. 18, n. 2, p. 113-118, 2004.

INSTITUTO BRASILEIRO DE GEOGRAFIA E ESTATÍSTICA. Educação: anos de estudos: distribuição das pessoas de 25 anos ou mais de idade, por grupos de anos de estudo - Brasil - 2007/2015. Rio de Janeiro: IBGE, 2015. Disponível em: <http://brasilemsintese.ibge.gov.br/pt/educacao/anos-de-estudo>. Acesso em: 08 jul. 2015.

MARCONI, Marina de Andrade; LAKATOS, Eva. Técnicas de pesquisa. 5 ed. São Paulo: Atlas, 2002.

SARLET, Ingo Wolfgang. Os direitos fundamentais sociais na constituição de 1988. Revista Diálogo Jurídico, Salvador, v. 1, n. 1, 2001. Disponível em:

<http://www.direitopublico.com.br/pdf_seguro/REVISTA-DIALOGOJURIDICO-01-2001-INGO-SARLET.pdf > . Acesso em: 04 jul. 2015.

SIERRA, Vânia Morales. A judicialização da política no Brasil e a atuação do assistente social na justiça. Revista Katálysis. Florianópolis, v. 14, n. 2, p. 256-264, jul./dez. 2011.

SILVEIRA, AdrianaDragone. A judicialização da educação para a efetivação do direito à educação básica. Jornal de Políticas

Educacionais, n. 9, p.30-40. jan./jun. 2011.

SILVEIRA, Adriana Dragone. Atuação do Tribunal de Justiça de São 
Paulo com relação ao direito de crianças e adolescentes à educação. Revista Brasileira de Educação, v. 17, n. 50, p. 353- 497, 2012.

VIANNA, Luiz Werneck; BURGOS, Marcelo Baumann; SALLES, Paula Martins. Dezessete anos de judicialização da política.Tempo Social, revista de sociologia da USP, v. 19, n. 2, p.39-85, nov. 2007. Disponível em:

<http://www.scielo.br/pdf/ts/v19n2/a02v19n2.pdf>.Acesso em: 26 jun. 2015.

VOLPE, Karina Rocha Martins. A judicialização dos direitos sociais estudos de caso na ótica do mínimo existencial. Espaço Jurídico, Joaçaba, v. 13, n. 1, p. 119-138, jan./jun. 2012. 